\title{
Freezing shortens the lifetime of DNA molecules under tension
}

\author{
Wei-Ju Chung ${ }^{1} \cdot$ Yujia Cui $^{1} \cdot$ Chi-Shuo Chen ${ }^{1}$ • \\ Wesley H. Wei ${ }^{2} \cdot$ Rong-Shing Chang ${ }^{1} \cdot$ Wun-Yi Shu ${ }^{3}$. \\ Ian C. Hsu ${ }^{1}$
}

Received: 8 March 2017 / Accepted: 16 August 2017 / Published online: 8 September 2017 (C) The Author(s) 2017. This article is an open access publication

\begin{abstract}
DNA samples are commonly frozen for storage. However, freezing can compromise the integrity of DNA molecules. Considering the wide applications of DNA molecules in nanotechnology, changes to DNA integrity at the molecular level may cause undesirable outcomes. However, the effects of freezing on DNA integrity have not been fully explored. To investigate the impact of freezing on DNA integrity, samples of frozen and non-frozen bacteriophage lambda DNA were studied using optical tweezers. Tension (5-35 pN) was applied to DNA molecules to mimic mechanical interactions between DNA and other biomolecules. The integrity of the DNA molecules was evaluated by measuring the time taken for single DNA molecules to break under tension. Mean lifetimes were determined by maximum likelihood estimates and variances were obtained through bootstrapping simulations. Under 5 $\mathrm{pN}$ of force, the mean lifetime of frozen samples is $44.3 \mathrm{~min}$ with $95 \%$ confidence interval (CI) between $36.7 \mathrm{~min}$ and $53.6 \mathrm{~min}$ while the mean lifetime of non-frozen samples is $133.2 \mathrm{~min}$ (95\% CI: $97.8-190.1 \mathrm{~min})$. Under $15 \mathrm{pN}$ of force, the mean lifetimes are $10.8 \mathrm{~min}$ (95\% CI: 7.6-12.6 min) and $78.5 \mathrm{~min}$ (95\% CI: 58.1-108.9 min). The lifetimes of frozen DNA molecules are significantly reduced, implying that freezing compromises DNA integrity. Moreover, we found that the reduced DNA structural integrity cannot be restored using regular
\end{abstract}

Yujia Cui

yjcui@mx.nthu.edu.tw

$\triangle$ Ian C. Hsu

ichsu@mx.nthu.edu.tw

1 Department of Biomedical Engineering and Environmental Sciences, National Tsing Hua University, 101, Section 2, Kuang-Fu Road, Hsinchu 30013, Taiwan

2 Department of Computer Science, Tufts University, 419 Boston Avenue, Medford, MA 02155, USA

3 Institute of Statistics, National Tsing Hua University, 101, Section 2, Kuang-Fu road, Hsinchu 30013, Taiwan 
ligation process. These results indicate that freezing can alter the structural integrity of the DNA molecules.

Keywords DNA freezing effect.DNA lifetime-DNA integrity-LambdaDNA - Single molecule - DNA nanotechnology

\section{Introduction}

DNA molecules have been widely used in various fields such as drug delivery, therapeutic systems, molecular imaging, and biomolecule detection recently due to their high mechanical flexibility and unique assembly specificity $[1,2]$. For example, aptamer, a short oligonucleotide, has been utilized to enhance the therapeutic efficiency of cancer treatments [3,4]. During reagent preparation, to maintain DNA quality and reduce DNA damage induced by free radicals in aqueous environments, DNA samples are usually stored at $-20{ }^{\circ} \mathrm{C}$ [5]. In ionizing radiation studies involving the use of long half-life isotopes, mixtures of DNA samples and isotopes have typically been frozen for up to 30 days at $-70{ }^{\circ} \mathrm{C}$ for ${ }^{125} \mathrm{I}$ compounds to accumulate sufficient isotope decays [6, 7]. Because of the common usage of freezing protocols, various engineering developments and scientific studies will benefit from understanding the effect of freezing DNA on its integrity.

The structural integrity of DNA plays a critical role in different nucleic acid nanotechnology applications. For example, site-specific DNA strands can be assembled into threedimensional nanostructures, which can serve as the building blocks of advanced nanodevices [8]. The structural stability of nucleotide probes can also influence hybridization efficiency for molecular detection. Various factors, such as ionic strength, can influence the integrity of molecular structures, and several technologies have been developed to probe the integrity of polynucleotides $[9,10]$. However, to probe the integrity of DNA at a single molecular level is still challenging for most current technologies.

In this study, we examined DNA integrity at the molecular level by using bacteriophage lambda DNA as a model molecule. Bacteriophage lambda DNA has been widely used in single-molecule experiments, with a few examples being the effect of force on intercalators [11-14], DNA binding of antibiotics [15], DNA-binding proteins [16-19], replication [20, 21], and structural changes under mechanical force [22, 23].

Double-strand breaks are often formed by closely spaced nicks. One method of detecting nicks, particularly if they are closely spaced, is to stretch the DNA molecules in a low ionic strength buffer. When DNA is stretched, sections containing clustered nicks denature locally and induce DSBs [24]. The integrity of DNA molecules is also influenced by the buffer being used. The ionic strength plays a major role in the stability of double-stranded DNA (dsDNA). Because DNA backbones are highly negatively charged in aqueous solutions, low salt concentrations result in a low degree of charge shielding of the backbones, thus making dsDNA less stable [25]. When dsDNA is subjected to external tension, low ionic strength buffers facilitate peeling and force induced melting near the nicks [26-28]. In addition, various surfactants, such as Tween 80 , are widely used for macromolecule assembly and nanostructure fabrication [29-31]. The effect of such surfactants on DNA integrity is not clear.

Although plasmid DNA samples can easily be prepared in house to ensure superior quality control, lambda DNA samples are usually sourced commercially. Lambda DNA (48,502 bp), which is several times larger than typical plasmids, is prone to chemical and mechanical 
damage during purification and storage. Some samples are frozen after purification and then thawed in the lab before being used in assays; although this freeze/thaw cycle does not affect most experiments, it can result in nicks that can skew the results of some experiments, especially if the DNA molecules are to be subjected to tension $[32,33]$.

In this study, we investigated the effects of freezing on DNA integrity at the molecular level by measuring the sustaining times of DNA molecules through the use of dual-beam optical tweezers. We analyzed the difference between frozen and non-frozen samples, as well as the difference between two batches of non-frozen samples.

\section{Materials and methods}

\subsection{Bacteriophage lambda DNA handling}

Bacteriophage lambda DNA samples were purchased from New England Biolabs (NEB, $\mathrm{N} 3011 \mathrm{~S})$. The standard catalog item was frozen at $-20^{\circ} \mathrm{C}$. The non-frozen samples were special order and shipped at $4{ }^{\circ} \mathrm{C}$. Upon arrival, the frozen sample was thawed and stored at $4{ }^{\circ} \mathrm{C}$. All lambda DNA samples were stored in $100 \mathrm{mM}$ Tris, $0.5 \mathrm{M} \mathrm{NaCl}$, and $50 \mathrm{mM}$ EDTA (pH 7.5) at $4{ }^{\circ} \mathrm{C}$. Samples older than 1 year were discarded.

Overhangs of lambda DNA $(14 \mu \mathrm{g})$ were annealed with complementary oligos with a single biotin at the $3^{\prime}$ end for $40 \mathrm{~min}$ in $50 \mu \mathrm{l}$ of TE buffer (10 mM Tris, $1 \mathrm{mM}$ EDTA, pH 8.0). Unbound oligos were washed twice with $50 \mathrm{mM}$ Tris $(\mathrm{pH} 7.5)$ with Amicon Ultra centrifugal filter (Millipore, UFC510096) at $8100 \mathrm{~g}$ for $15 \mathrm{~min}$ at $4{ }^{\circ} \mathrm{C}$. All samples were then treated by 400 units of T4 DNA ligase (NEB, M0202S) to repair nicks at $16{ }^{\circ} \mathrm{C}$ for $2.5 \mathrm{~h}$ in $40-50 \mu \mathrm{l}$ of 1X T4 DNA ligase buffer (50 mM Tris- $\mathrm{HCl}, 10 \mathrm{mM} \mathrm{MgCl}_{2}, 10 \mathrm{mM}$ DTT, and $1 \mathrm{mM}$ ATP, $\mathrm{pH} 7.5$ ) in PCR tubes. T4 DNA ligase was inactivated with additional $6 \mu \mathrm{l}$ of $0.5 \mathrm{M}$ EDTA (pH 8.0) to bring the final concentration to 53-65 $\mathrm{mM}$ and washed with TE buffer twice with centrifugal filter at $8100 \times \mathrm{g}$ for $15 \mathrm{~min}$ at $4{ }^{\circ} \mathrm{C}$. The final products were stored in $100 \mathrm{mM}$ Tris, $0.5 \mathrm{M} \mathrm{NaCl}$, and $10 \mathrm{mM}$ EDTA $(\mathrm{pH} 7.5)$ at $4{ }^{\circ} \mathrm{C}$ and used within 2 weeks.

\subsection{Optical tweezers setup}

The instrument setup was described by Yang et al. [34]. In short, the force-measuring dualbeam laser tweezers comprised one fixed trap and one movable trap, both formed by 1064-nm laser beams. A quadrant photodiode (QPD) was used to measure the signal from the position of the bead in the trap from an 830-nm defocused laser beam that was superimposed onto the fixed trap. Trap stiffness was calculated from the Brownian motion of the bead in the trap (Fig. 1a).

Labeled lambda DNA was incubated with streptavidin-coated beads (Spherotech, SVP-155) for approximately $1 \mathrm{~h}$ before being sealed in a liquid chamber containing TE buffer (10 $\mathrm{mM}$ Tris, $1 \mathrm{mM}$ EDTA, $53 \mathrm{mM} \mathrm{NaCl}$, and $0.3 \mathrm{mg} / \mathrm{ml}$ casein, $\mathrm{pH} 8.0$ ) at $23{ }^{\circ} \mathrm{C}$, with or without 4.6\% Tween 80 (Sigma-Aldrich, P5188). Two beads were trapped, with a single DNA molecule suspended in between (Fig. 1a). The DNA molecule was then stretched to the desired tension by moving the movable trap. The force was deduced from the trap stiffness and the average position of the bead in the fixed trap.

Sustaining time was defined as the time required for a single DNA molecule to break under tension. In this type of measurement, a drop to zero in the force measurement indicated that the 

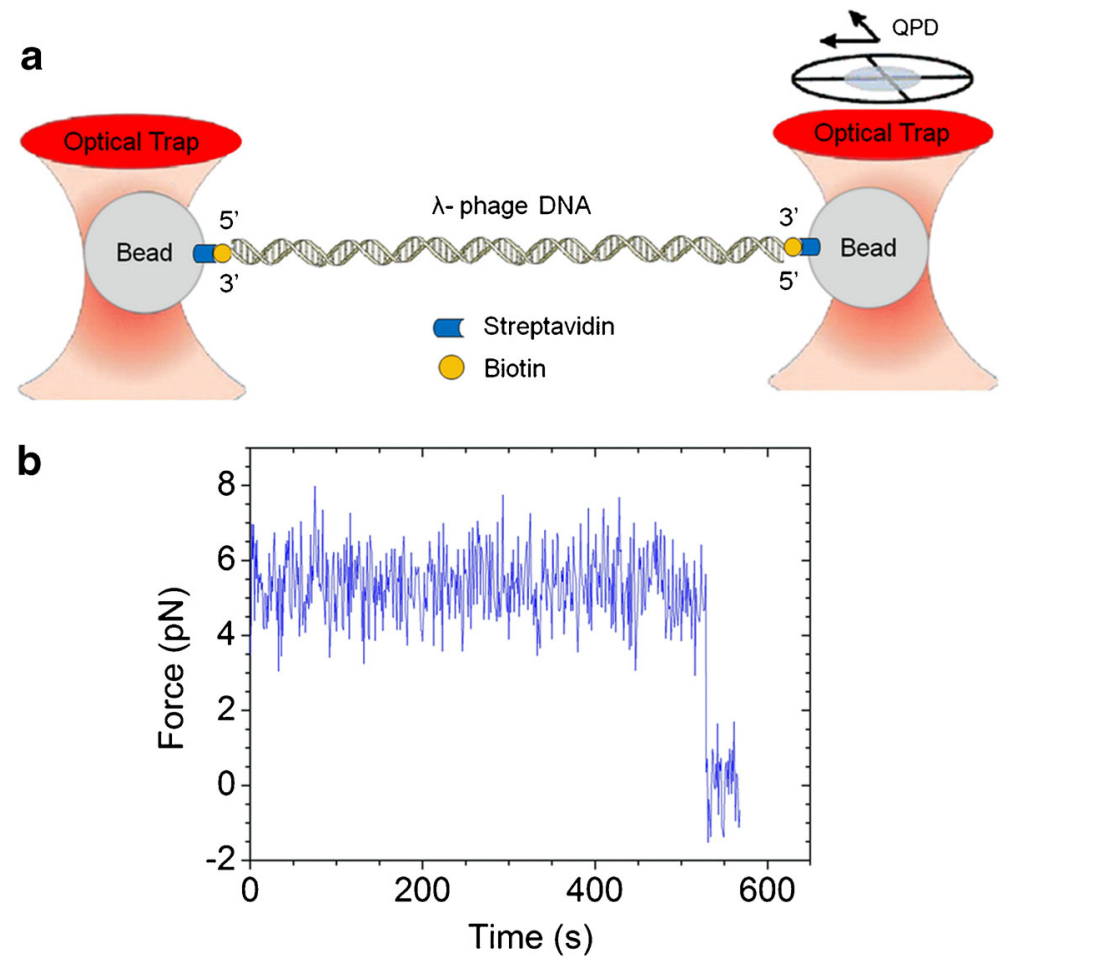

Fig. 1 Measurement of sustaining time. a Schematic presentation of a single DNA molecule subjected to a constant force in dual-beam optical tweezers. The figure also illustrates the dumbbell structure of streptavidincoated polystyrene beads with biotinylated lambda DNA between them. Both traps were formed by a neodymium-doped yttrium orthovanadate (Nd:YVO4) laser (1064 nm, Spectra-Physics). One beam was controlled by an acoustic-optical deflector (AOD, IntraAction Corp) to apply tension, and the other served as a fixed trap. The displacement of the bead in the fixed trap was detected by a QPD (model SPOT-9DMI, UDT), and used to calculate the force applied to the DNA molecule. b Sample trace of a single lambda DNA molecule subjected to a constant force. The force was $5.3 \pm 0.9 \mathrm{pN}$, and the sustaining time was $528 \mathrm{~s}$

DNA molecule had broken (Fig. 1b). The cutoff time for measuring the DNA sustaining time was set to $60 \mathrm{~min}$ in this study.

\subsection{Data analysis}

The probability that a DNA molecule survives time $t$ was derived as follows $[35,36]$ :

$$
P_{\text {model }}(t)=e^{-t / \tau}
$$

where $\tau$ is the mean lifetime of DNA. This survival probability was estimated by:

$$
P_{\text {data }}(t)=\frac{n(t)}{N}
$$

where $n(t)$ is the number of DNA molecules not broken by time $t$, and $N$ is the total number of molecules tested. The maximum likelihood estimate (MLE) of $\tau$ for the exponential probability distribution with censoring was given by: 


$$
\hat{\tau}=\frac{\sum_{i=1}^{n} x_{i}+T_{w}(N-n)}{n}
$$

where $x_{i}$ is the sustaining time of broken DNA, $T_{w}$ is the period of measurement window (= $60 \mathrm{~min}$ in the study), $n$ is the number of broken DNA molecules during the measurement period. The sampling distribution of $\hat{\tau}$ could be approximated by bootstrapping as follows: We generated 10,000 bootstrap samples, each of size $N$, from the exponential distribution with $\tau=\hat{\tau}$. For each of these samples, the maximum likelihood estimate, $\hat{\tau_{b}}$, of $\tau$ for the exponential distribution with censoring was calculated. The significance of differences among $\tau$ 's for various experimental conditions could be evaluated by their $95 \%$ confidence intervals (CI).

\section{Results}

\subsection{Comparison of frozen and non-frozen samples}

To evaluate the effects of the freezing protocol, frozen and non-frozen samples were compared in low-force experiments. The sustaining times of the frozen and non-frozen lambda DNA molecules were measured under tensile forces of 5 and $15 \mathrm{pN}$ in low salt buffer. Mean DNA lifetime $\hat{\tau}$ was calculated according to Eq. (3). We evaluated the variance of lifetime under different exponential conditions using bootstrapping simulations. The results for frozen and non-frozen DNA molecules are shown in Table 1.

Survival probability plots were generated by plotting survival probabilities versus time, see Fig. 2a-c. Survival probabilities from experiments are represented by blue squares. The green line is the exponential decay function with $\hat{\tau}$ as decay constant. For each experimental condition, the distributions of those 10,000 bootstrap estimates of mean lifetime were plotted. The results for $5 \mathrm{pN}$ are shown in Fig. 2d. The distribution of frozen DNA samples is distinct from both non-frozen samples under the same tension. Although the mean of the two nonfrozen samples are different, their $95 \%$ confidence intervals overlap. Our data indicated that there is a significant difference between frozen and non-frozen samples, and no significant difference between samples stored in TE buffer and TE with Tween 80. Bootstrap simulations

Table 1 MLE and variance of the mean lifetimes for frozen and non-frozen DNA samples under low force

\begin{tabular}{|c|c|c|c|c|c|c|c|c|}
\hline \multirow{2}{*}{$\begin{array}{l}\text { Force } \\
\text { DNA source }\end{array}$} & \multicolumn{4}{|l|}{$5 \mathrm{pN}$} & \multicolumn{4}{|l|}{$15 \mathrm{pN}$} \\
\hline & $\begin{array}{l}\text { Mean } \\
\text { lifetime } \tau \\
(\min )\end{array}$ & $\begin{array}{l}95 \% \text { CI } \\
(\mathrm{min})\end{array}$ & $\begin{array}{l}\% \text { of } \\
\text { sustaining time } \\
\text { over } 60 \mathrm{~min}\end{array}$ & $\mathrm{~N}^{*}$ & $\begin{array}{l}\text { Mean } \\
\text { lifetime } \tau \\
(\min )\end{array}$ & $\begin{array}{l}95 \% \mathrm{CI} \\
(\mathrm{min})\end{array}$ & $\begin{array}{l}\% \text { of } \\
\text { sustaining time } \\
\text { over } 60 \mathrm{~min}\end{array}$ & $\mathrm{~N}^{*}$ \\
\hline Frozen in TE & 44.3 & $36.7-53.6$ & $29 \%$ & 143 & 10.8 & 7.6-12.6 & $0 \%$ & 60 \\
\hline $\begin{array}{l}\text { Non-frozen in } \\
\text { TE }\end{array}$ & 133.2 & 97.8-190.1 & $62 \%$ & 100 & 78.5 & $58.1-108.9$ & $47 \%$ & 76 \\
\hline $\begin{array}{l}\text { Non-frozen in } \\
\text { TE with } \\
\text { Tween } 80\end{array}$ & 105.5 & $79.1-145.7$ & $55 \%$ & 100 & 75.1 & $58.0-98.6$ & $42 \%$ & 100 \\
\hline
\end{tabular}

*Total number of DNA molecules studied 

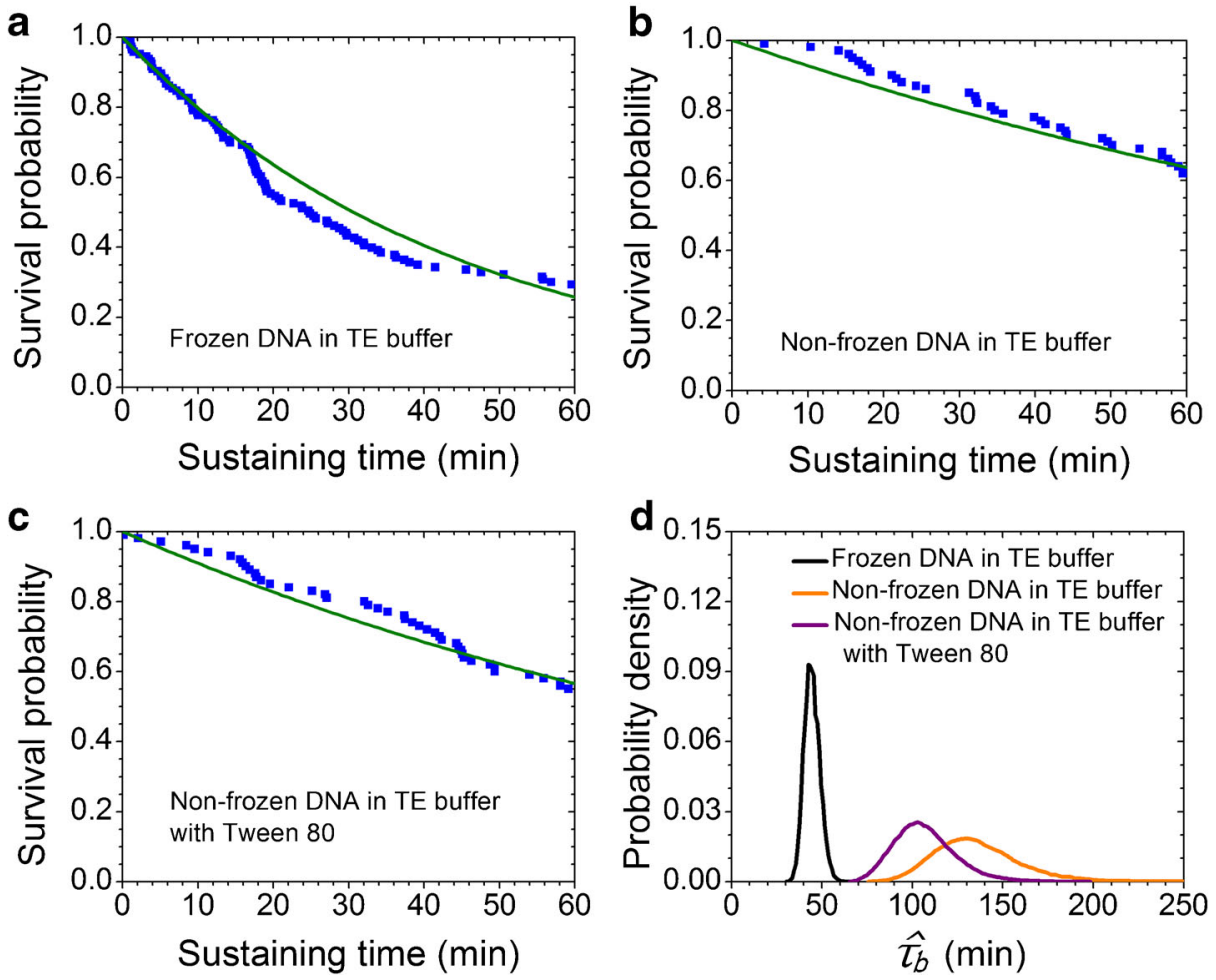

Fig. 2 Survival probabilities of different DNA samples subjected to force of $5 \mathrm{pN}$. The horizontal axis for a to c is sustaining time of DNA and the vertical axis is survival probability. The blue squares represent the DNA sustaining time within the measurement window, and the green lines show the single exponential decay function with mean lifetime $\tau$ derived from maximum likelihood estimation. a Frozen DNA in TE buffer. There were 143 molecules examined and the MLE estimated lifetime is $44.3 \mathrm{~min}$ (95\% CI: 36.7-53.6 min). b Non-frozen DNA in TE buffer. There were 100 molecules examined and the MLE estimated lifetime is 133.2 min (95\% CI: $97.8-$ $190.1 \mathrm{~min})$. c Non-frozen DNA in TE buffer with $4.6 \%$ Tween 80 . There were 100 molecules examined and the MLE estimated lifetime is $105.5 \mathrm{~min}$ (95\% CI: 79.1-145.7 min). d The probability density, as approximated by bootstrapping, of the sampling distributions of $\hat{\tau}$ under various experimental conditions, where $\tau_{b}$ is the maximum likelihood estimate of $\tau$ calculated from the bootstrap sample with censoring

for $15 \mathrm{pN}$ show similar results. The $95 \%$ confidence intervals of sampling distribution from bootstrapping of the frozen sample separate completely from those of the non-frozen samples.

Regarding the data derived for the samples in TE buffer at a tensile force of $5 \mathrm{pN}$, the only difference between the samples was that the frozen samples were stored and shipped at $-20{ }^{\circ} \mathrm{C}$, whereas the non-frozen samples were maintained at $4{ }^{\circ} \mathrm{C}$. The results of MLE lifetime show that frozen samples have a shorter lifetime $(44.3 \mathrm{~min}, 95 \% \mathrm{CI}: 36.7-53.6 \mathrm{~min})$, then nonfrozen samples in the same buffer (133.2 $\mathrm{min}, 95 \%$ CI: $97.8-190.1 \mathrm{~min}$ ) (Table 1). Only $29 \%$ of the frozen DNA molecules lasted more than 60 min under the $5 \mathrm{pN}$ force, whereas $62 \%$ of the non-frozen samples in TE buffer lasted more than 60 min under this force.

We studied the effects of surfactants on DNA integrity by using non-frozen lambda DNA with additional Tween $80(4.6 \%)$ in the liquid chamber. Compared with a sample without Tween 80 , the lifetime of the non-frozen samples was slightly shortened to around $105.5 \mathrm{~min}$ (95\% CI: 79.1-145.7 $\mathrm{min}$ ), and the number of molecules that survived past $60 \mathrm{~min}$ in the sample with Tween 80 dropped slightly from $62 \%$ to $55 \%$. Despite the $21 \%$ reduction in the 
DNA lifetime in the presence of Tween 80, the shortened lifetime was still more than two times longer than that of the frozen samples in TE buffer.

To further investigate the mechanical strength of the DNA molecules, we increased the tension exerted on the molecules. We observed the differences in lifetime between the frozen and non-frozen samples under a force of $15 \mathrm{pN}$. All the frozen samples in TE buffer broke within $60 \mathrm{~min}$ and $47 \%$ of the non-frozen samples in TE buffer survived over $60 \mathrm{~min}$. The addition of Tween 80 slightly reduced the amount of samples that survived past the $60 \mathrm{~min}$ mark to $42 \%$. The lifetime of the frozen samples was $10.8 \mathrm{~min}$ (95\% CI: 7.6-12.6 min), considerably shorter than that of the non-frozen samples (78.5 min, 95\% CI: 58.1-108.9 min).

Increasing the mechanical force shortened the lifetimes of the molecules, an observation that is consistent with those reported in the literature [37, 38]. Because the non-frozen samples subjected to the 5 and $15 \mathrm{pN}$ force experiments were derived from the same batch of lambda DNA, the differences in their lifetimes should be directly related to the different tensile forces
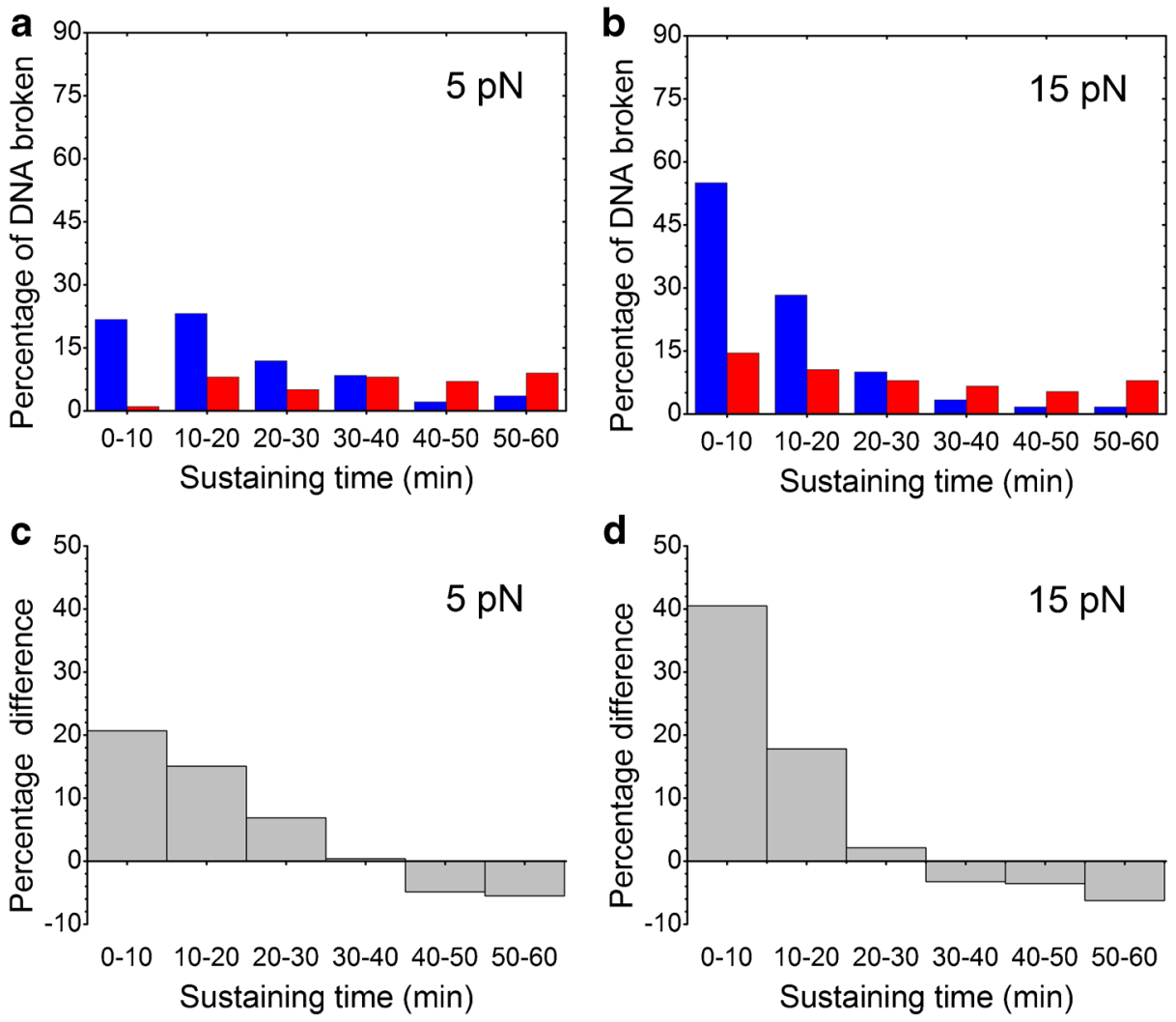

Fig. 3 Sustaining times of frozen and non-frozen lambda DNA samples under constant tension. The $x$-axis represents the DNA sustaining time $(\mathrm{min})$, and the $y$-axis represents the percentage of all DNA molecules tested in TE buffer. Blue histograms represent frozen DNA samples, and red histograms represent non-frozen samples. a Histogram for frozen samples subjected to a tensile force of $5.0 \pm 0.7 \mathrm{pN}$ and non-frozen samples subjected to a force of $5.3 \pm 1.1 \mathrm{pN}$. b Histogram for frozen samples subjected to a force of $15.3 \pm 1.5 \mathrm{pN}$ and non-frozen samples to a force of $15.1 \pm 0.7 \mathrm{pN}$. $\mathbf{c}$ Differences in the percentage of broken DNA between frozen and nonfrozen samples at $5 \mathrm{pN}$. d Differences in the percentage of broken DNA between frozen and non-frozen samples at $15 \mathrm{pN}$ 
applied. Moreover, this result implies that the freezing protocol made the DNA molecules more fragile under higher tension.

The histograms of the sustaining time are illustrated in Fig. 3a and b. All data within a histogram were derived from the same batch. Histograms of the frozen samples are presented in blue and those of the non-frozen samples are presented in red. For easy comparison, the numbers of DNA breakage events were replaced by the percentages of DNA molecules that were broken during the first 60 min of the experiments.

Figure 3a presents a comparison of the distributions of the sustaining times of the frozen and non-frozen DNA samples at $5 \mathrm{pN}$. From 0 to $30 \mathrm{~min}$, more frozen DNA molecules were broken, compared with the non-frozen molecules. A lower percentage of frozen DNA molecules exhibited breakage between 40 and $60 \mathrm{~min}$, presumably because most of the frozen molecules had already broken before this period. By contrast, the non-frozen samples exhibited a more even distribution across the 60-min observation, except for the first $10 \mathrm{~min}$, during which only $1 \%$ broke. The differences in the sustaining time histograms between the two sample groups are shown in Fig. 3c. The greatest difference was observed within the first $10 \mathrm{~min}$, decreasing as the sustaining time increases, and finally reaching a negative level after $40 \mathrm{~min}$.

Similar differences were also observed between the frozen and non-frozen samples at 15 $\mathrm{pN}$. Compared with the percentage observed at $5 \mathrm{pN}$, a greater percentage (55 vs. 22\%) of the frozen DNA molecules broke within the first $10 \mathrm{~min}$ (Fig. 3b). After $20 \mathrm{~min}$, most of the frozen molecules had already broken. For the non-frozen samples, more molecules were broken within 10 min compared with the results observed at $5 \mathrm{pN}$ for samples from the same batch; however, approximately three-fourths of the molecules survived beyond $20 \mathrm{~min}$. The differences between the two histograms are illustrated in Fig. 3d. Similar to the differences in Fig. $3 \mathrm{c}$, the differences decreased as the sustaining time increased. After $30 \mathrm{~min}$, most of the frozen molecules had already broken, thus resulting in fewer molecules to be observed.

The lifetimes of the frozen lambda molecules were observed to be significantly shorter than those of the non-frozen samples at 5 and $15 \mathrm{pN}$. Our data show that the freezing process, even without repeated freeze/thaw cycles, made a significant impact on DNA integrity when tested in a tensile force range common in biologically relevant processes.

\subsection{Comparison of non-frozen samples from different batches}

The sustaining times of non-frozen DNA samples from two batches purchased from the same vendor were measured at 25 and $35 \mathrm{pN}$ to ensure that most, if not all, molecules would break before the cutoff time (Table 2). All samples were processed in exactly the same manner from their arrival in the lab to their loading in liquid chambers; moreover, all buffers used were the same. A single exponential decay probability function with MLE lifetime do not fit data sets well, as shown by green lines in Fig. 4a and b. The red lines in Fig. 4a and b show that the sum of two exponential decay functions is a much better fit for the data, which implies that more than one mechanism may contribute to the observed DNA breakage. Because all DNA molecules tested broke within the measurement window of $60 \mathrm{~min}$ for both batches, it is not necessary to apply the MLE method. Sample lifetimes were calculated by fitting the survival probability plots to the sum of two exponential decay functions.

Most of the molecules from both batches that were tested at the relatively high tensile forces of 25 and $35 \mathrm{pN}$ broke within 60 min. The samples subjected to the 25 and $35 \mathrm{pN}$ forces exhibited two discrete populations, a shorter lifetime group and a longer lifetime group. The 


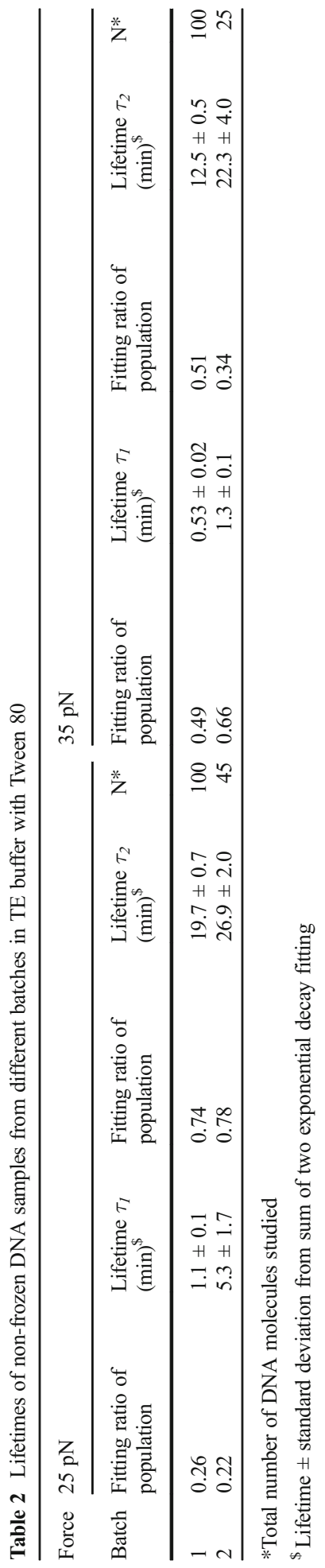



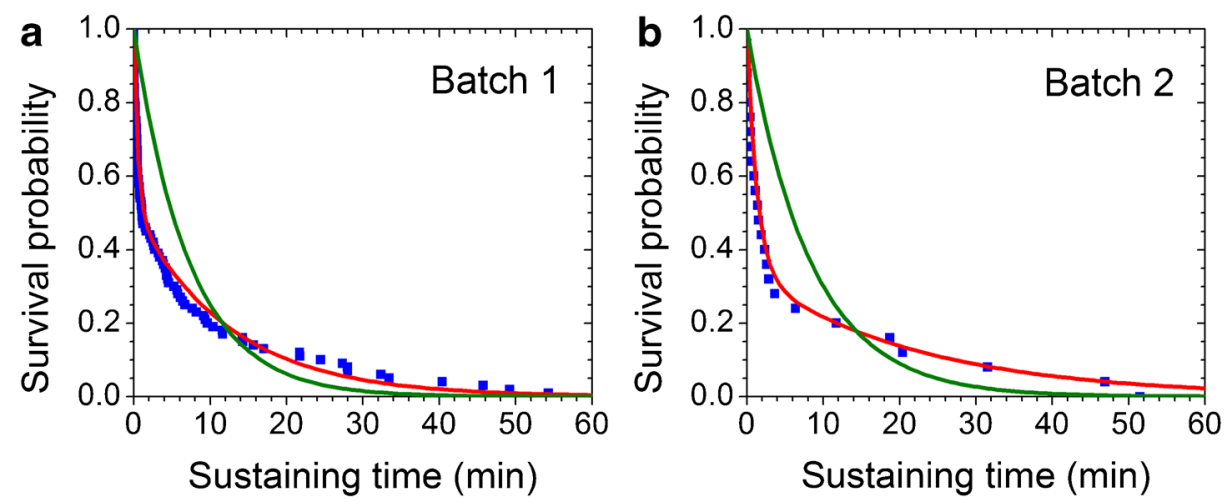

Fig. 4 Survival probability of different DNA batches under $35 \mathrm{pN}$ of force. The horizontal and vertical axes are sustaining time and survival probability of DNA. The blue squares represent DNA sustaining times observed in experiments. The green lines show the single exponential decay function with the MLE estimated lifetime $\tau$, the red lines show the sum of two exponential fitting for data. a Batch 1 of non-frozen DNA (100 molecules) in TE buffer with $4.6 \%$ Tween 80 . The MLE estimated lifetime was $7.2 \mathrm{~min}$. The sum of two exponential decay fitting gave lifetimes of $0.53 \pm 0.02 \mathrm{~min}$ and $12.5 \pm 0.5 \mathrm{~min}$. b Batch 2 of non-frozen DNA (25 molecules) in TE buffer with $4.6 \%$ Tween 80 . The MLE estimated lifetime was $8.3 \mathrm{~min}$. The sum of two exponential decay fitting gave lifetimes of $1.3 \pm 0.1 \mathrm{~min}$ and $22.3 \pm 4.0 \mathrm{~min}$

effects of the applied forces on both batches were also similar. Specifically, the lifetimes of the samples from both batches were shortened when the tensile force increased from 25 to $35 \mathrm{pN}$. At $25 \mathrm{pN}$, batch 1 had lifetimes of $1.1 \pm 0.1 \mathrm{~min}$ and $19.7 \pm 0.7 \mathrm{~min}$, whereas batch 2 had lifetimes of $5.3 \pm 1.7 \mathrm{~min}$ and $26.9 \pm 2.0 \mathrm{~min}$. The differences were within the same order of magnitude and show no significant difference. The same trend was also observed at $35 \mathrm{pN}$. Batch 1 had lifetimes of $0.53 \pm 0.02 \mathrm{~min}$ and $12.5 \pm 0.5 \mathrm{~min}$, whereas batch 2 had lifetimes of $1.3 \pm 0.1 \mathrm{~min}$ and $22.3 \pm 4.0 \mathrm{~min}$. Overall, under the same tension, DNA in batch 2 had a longer lifetime than did that in batch 1 , indicating that it was of higher quality in terms of structural integrity.

For batch 1 , at $25 \mathrm{pN}, 26 \%$ of the tested molecules were in the shorter lifetime group; the remaining molecules were in the longer lifetime group. When the tensile force increased to 35 $\mathrm{pN}$, the sizes of the two populations evened out. For batch 2, although two populations were also observed, the profile was different from that observed for batch 1 at both forces. At $25 \mathrm{pN}$, a lower percentage of the tested molecules belonged to the shorter lifetime group (22 vs. $26 \%$ ). At $35 \mathrm{pN}$, more than half of the molecules belonged to the shorter lifetime group.

The histogram of the sustaining time shows the distributions of the populations within each sample. The histograms of the sustaining times of non-frozen lambda DNA molecules from the two batches are illustrated in Fig. 5a and b. All data within a histogram were derived from a single batch. The histograms of the samples from batch 1 are presented in blue and those of the samples from batch 2 are presented in red. For easy comparison, the numbers of DNA breakages were replaced by the percentages of DNA molecules that were broken during the first 60 min of the experiments.

Figure 5a presents a comparison of the distributions of the sustaining times of the nonfrozen DNA samples at $25 \mathrm{pN}$, and Fig. 5c illustrates the difference between the two histograms. From 0 to $10 \mathrm{~min}$, more DNA molecules broke in batch 1 than in batch 2 . From 10 to $40 \mathrm{~min}$, a lower percentage of DNA molecules from batch 1 broke, presumably because most of the molecules that had been frozen had already broken within $40 \mathrm{~min}$. From 40 to $60 \mathrm{~min}$, the number of molecules observable from both samples was extremely low; thus, the 

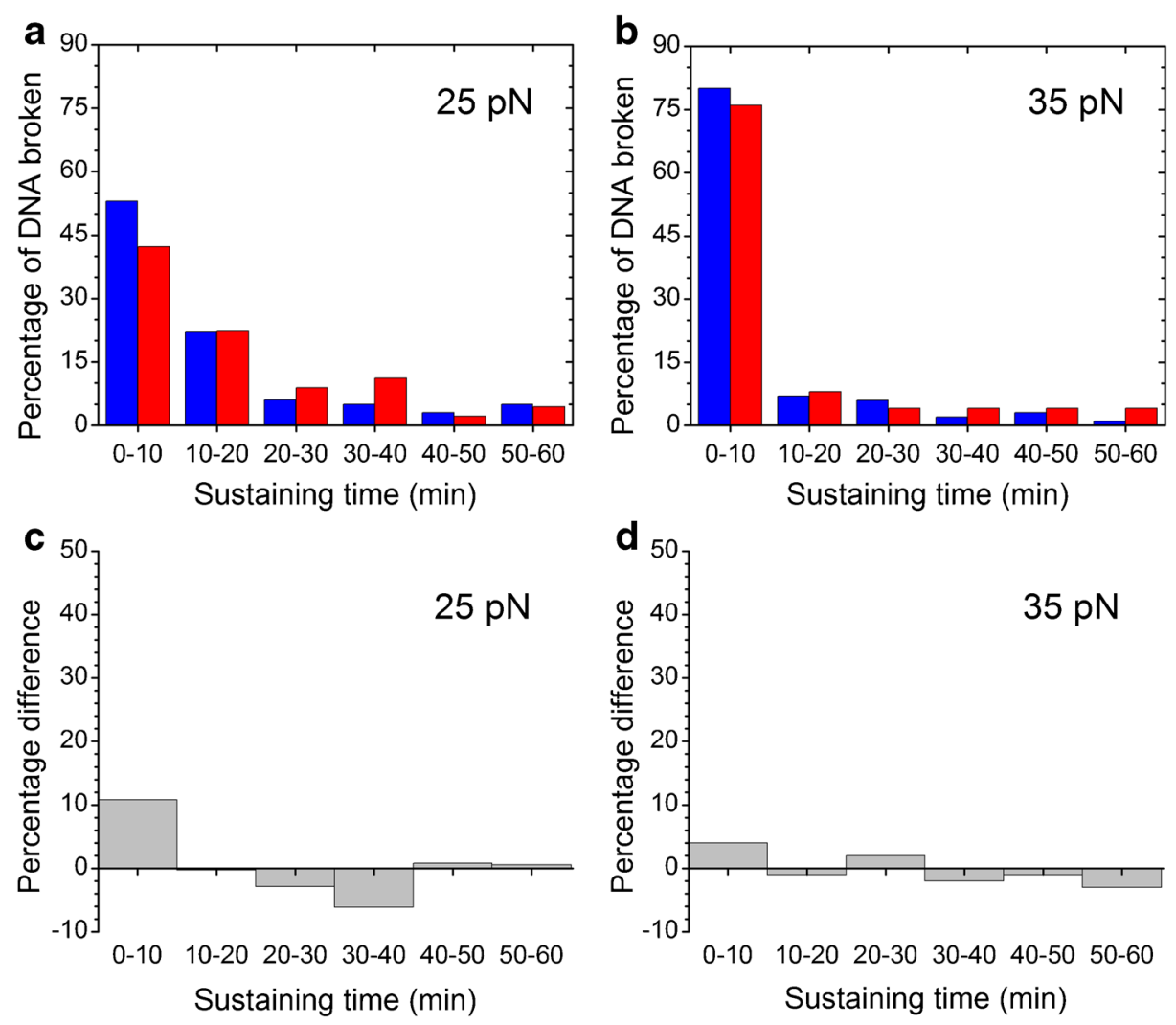

Fig. 5 Sustaining times of non-frozen lambda DNA samples under 25 and $35 \mathrm{pN}$ tension. The $x$-axis represents the DNA sustaining time ( $\mathrm{min}$ ), and the $y$-axis represents the percentage of all DNA molecules tested in TE buffer with $4.6 \%$ Tween 80 . Blue histograms denote samples from batch 1, and red histograms denote samples from batch 2 in $\mathbf{a}$ and $\mathbf{b}$. a Of 100 molecules tested from batch 1 at a tensile force of $24.6 \pm 1.9 \mathrm{pN}, 6 \%$ lasted over $60 \mathrm{~min}$. Of 45 molecules tested from batch 2 at a tensile force of $24.9 \pm 1.0 \mathrm{pN}, 9 \%$ lasted over $60 \mathrm{~min}$. b Of 100 molecules tested from batch 1 at a tensile force of $34.9 \pm 1.8 \mathrm{pN}$, only one lasted over $60 \mathrm{~min}$. All 25 molecules tested from batch 2 at a tensile force of $34.7 \pm 1.7 \mathrm{pN}$ were broken within $60 \mathrm{~min}$. $\mathbf{c}$ Differences in the percentages of broken DNA between the two batches of non-frozen DNA samples at a tensile force of $25 \mathrm{pN}$. d Differences in the percentages of broken DNA between the two batches of non-frozen DNA at a tensile force of $35 \mathrm{pN}$

fluctuation may not bear any statistical significance. The histograms of the two batches at 35 $\mathrm{pN}$ are shown in Fig. 5b. The difference in the sustaining time histograms between the two sample groups at $35 \mathrm{pN}$ is presented in Fig. $5 \mathrm{~d}$. The greatest difference was observed within the first $10 \mathrm{~min}$. Beyond that time, the size of the sample was too small for us to draw clear conclusions.

\section{Discussion and conclusions}

The considerable difference in lifetime between the frozen and non-frozen DNA samples at a low force could have a few underlying causes. We speculate that the most likely cause is the higher number of nicks in the frozen sample, which consequently makes it more likely to have 
a pair of closely spaced nicks on opposite strands. In low ionic strength buffer, a pulling force is conducive to breathing/peeling in dsDNA $[39,40]$ and accelerates the breaking process near closely spaced nicks. Our data indicate that the frozen DNA specimens had lower mechanical strength levels, which is consistent with previous findings for DNA at low temperatures [10].

DNA ligase is frequently used in laboratories to facilitate the formation of phosphodiester bonds of adjacent DNA bases, and ligation is expected to enhance DNA integrity. In our experiments, T4 DNA ligase is applied to repair the nicks of both the frozen and non-frozen samples as part of the biotinylation procedure, and this ligation procedure is expected to repair the nicks along the DNA structure.

The ligation condition used in this study, $16{ }^{\circ} \mathrm{C}$ for $2.5 \mathrm{~h}$, is shorter than the recommended ligation time in the manufacturer's protocol, and a more optimized ligation procedure may produce frozen samples with longer lifetimes. On the other hand, we cannot ignore the possibility that ligation procedures may not be able to fully restore the damages caused by freezing DNA samples. Therefore, if intended experiments rely on DNA integrity, avoiding samples that have been frozen is worthwhile.

Non-frozen samples offer higher DNA integrity than frozen samples do, but long DNA molecules from different batches still show different survivorship profiles under tension. In contrast to lower tensile force $(5-15 \mathrm{pN})$, two discrete populations with different decay lifetimes were observed under higher tensile force $(25-35 \mathrm{pN})$. These results suggest that more than one single factor may contribute to the DSBs, and we speculate that various DSBs mechanisms, such as bubble migration and strand peeling [28, 41], could contribute to the observed DSBs in our experiments. It is also possible that the rupture of single biotin-streptavidin binding between DNA and beads [42] contributes to the additional population as well. More experiments are needed to further explore the potential mechanisms of the DNA breakage under higher tensile force. Due to batch-to-batch differences, care should be taken to perform all experiments from one batch.

We used dual-beam optical tweezers to evaluate the integrity of DNA molecules by stretching single molecules in low ionic strength buffers. Our results demonstrate that common freezing protocols can reduce DNA integrity at the molecular level. When a moderate tensile force $(<20$ $\mathrm{pN}$ ) was applied to mimic the mechanical interactions between enzymes and DNA molecules, the lifetimes of frozen DNA molecules decreased dramatically. Considering the increasing applications of DNA molecules in numerous fields, our findings are expected to aid developments in sample preparation and storage procedures in DNA nanotechnology.

Acknowledgements We would like to thank Chen, Ruei-He for running the bootstrap simulations. This research was funded by the Ministry of Science and Technology, Taiwan, grant number MOST 104-2112-M$007-016$.

Funding This study was funded by the Ministry of Science and Technology, Taiwan, grant number MOST 104-2112-M-007 -016.

Compliance with ethical standards There were no human participants and/or animals involved in this research.

Conflict of interest The authors declare that they have no conflicts of interest.

Open Access This article is distributed under the terms of the Creative Commons Attribution 4.0 International License (http://creativecommons.org/licenses/by/4.0/), which permits unrestricted use, distribution, and reproduction in any medium, provided you give appropriate credit to the original author(s) and the source, provide a link to the Creative Commons license, and indicate if changes were made. 


\section{References}

1. Chen, Y.J., Groves, B., Muscat, R.A., Seelig, G.: DNA nanotechnology from the test tube to the cell. Nat. Nanotechnol. 10(9), 748-760 (2015). https://doi.org/10.1038/nnano.2015.195

2. Walsh, A.S., Yin, H., Erben, C.M., Wood, M.J., Turberfield, A.J.: DNA cage delivery to mammalian cells. ACS Nano 5(7), 5427-5432 (2011). https://doi.org/10.1021/nn2005574

3. Keefe, A.D., Pai, S., Ellington, A.: Aptamers as therapeutics. Nat. Rev. Drug Discov. 9(7), 537-550 (2010). https://doi.org/10.1038/nrd3141

4. Tan, W., Wang, H., Chen, Y., Zhang, X., Zhu, H., Yang, C., Yang, R., Liu, C.: Molecular aptamers for drug delivery. Trends Biotechnol. 29(12), 634-640 (2011). https://doi.org/10.1016/j.tibtech.2011.06.009

5. Green, M.R., Sambrook, J.: Isolation and Quantification of DNA. In: Inglis, J., Boyle, A., Gann, A. (eds.) Molecular Cloning: a Laboratory Manual. pp. 1-78. Cold Spring Harbor, New York (2012)

6. Gaidamakova, E.K., Neumann, R.D., Panyutin, I.G.: Site-specific strand breaks in RNA produced by (125)I radiodecay. Nucleic Acids Res. 30(22), 4960-4965 (2002)

7. Panyutin, I.G., Neumann, R.D.: Radioprobing of DNA: distribution of DNA breaks produced by decay of 125I incorporated into a triplex-forming oligonucleotide correlates with geometry of the triplex. Nucleic Acids Res. 25(4), 883-887 (1997)

8. Michelotti, N., Johnson-Buck, A., Manzo, A.J., Walter, N.G.: Beyond DNA origami: the unfolding prospects of nucleic acid nanotechnology. Wiley Interdiscip. Rev. Nanomed. Nanobiotechnol. 4(2), 139152 (2012). https://doi.org/10.1002/wnan.170

9. Tsukanov, R., Tomov, T.E., Liber, M., Berger, Y., Nir, E.: Developing DNA nanotechnology using singlemolecule fluorescence. Acc. Chem. Res. 47(6), 1789-1798 (2014). https://doi.org/10.1021/ar500027d

10. Grecz, N., El-Zawahry, Y.A.: Effect of radiation and freezing on [3H]DNA of Yersinia enterocolitica. Appl. Environ. Microbiol. 47(5), 1101-1105 (1984)

11. Bazoni, R.F., Lima, C.H., Ramos, E.B., Rocha, M.S.: Force-dependent persistence length of DNAintercalator complexes measured in single molecule stretching experiments. Soft Matter 11(21), 43064314 (2015). https://doi.org/10.1039/c5sm00706b

12. Almaqwashi, A.A., Andersson, J., Lincoln, P., Rouzina, I., Westerlund, F., Williams, M.C.: Dissecting the dynamic pathways of stereoselective DNA threading intercalation. Biophys. J. 110(6), 1255-1263 (2016). https://doi.org/10.1016/j.bpj.2016.02.016

13. Almaqwashi, A.A., Paramanathan, T., Lincoln, P., Rouzina, I., Westerlund, F., Williams, M.C.: Strong DNA deformation required for extremely slow DNA threading intercalation by a binuclear ruthenium complex. Nucleic Acids Res. 42(18), 11634-11641 (2014). https://doi.org/10.1093/nar/gku859

14. Almaqwashi, A.A., Paramanathan, T., Rouzina, I., Williams, M.C.: Mechanisms of small molecule-DNA interactions probed by single-molecule force spectroscopy. Nucleic Acids Res. 44(9), 3971-3988 (2016). https://doi.org/10.1093/nar/gkw237

15. Paramanathan, T., Vladescu, I., McCauley, M.J., Rouzina, I., Williams, M.C.: Force spectroscopy reveals the DNA structural dynamics that govern the slow binding of actinomycin D. Nucleic Acids Res. 40(11), 4925-4932 (2012). https://doi.org/10.1093/nar/gks069

16. Graham, J.S., Johnson, R.C., Marko, J.F.: Concentration-dependent exchange accelerates turnover of proteins bound to double-stranded DNA. Nucleic Acids Res. 39(6), 2249-2259 (2011). https://doi. org/10.1093/nar/gkq1140

17. van Loenhout, M.T., De Vlaminck, I., Flebus, B., den Blanken, J.F., Zweifel, L.P., Hooning, K.M., Kerssemakers, J.W., Dekker, C.: Scanning a DNA molecule for bound proteins using hybrid magnetic and optical tweezers. PLoS One 8(6), e65329 (2013). https://doi.org/10.1371/journal. pone.0065329

18. Liebesny, P., Goyal, S., Dunlap, D., Family, F., Finzi, L.: Determination of the number of proteins bound non-specifically to DNA. J. Phys. Condens. Matter 22(41), 414104 (2010). https://doi.org/10.1088/09538984/22/41/414104

19. Murugesapillai, D., McCauley, M.J., Maher 3rd, L.J., Williams, M.C.: Single-molecule studies of highmobility group B architectural DNA bending proteins. Biophys. Rev. 9(1), 17-40 (2017). https://doi. org/10.1007/s12551-016-0236-4

20. Kulczyk, A.W., Tanner, N.A., Loparo, J.J., Richardson, C.C., van Oijen, A.M.: Direct observation of enzymes replicating DNA using a single-molecule DNA stretching assay. J. Vis. Exp. 37, 1689 (2010). https://doi.org/10.3791/1689

21. Hamdan, S.M., Loparo, J.J., Takahashi, M., Richardson, C.C., van Oijen, A.M.: Dynamics of DNA replication loops reveal temporal control of lagging-strand synthesis. Nature 457(7227), 336-339 (2009). https://doi.org/10.1038/nature07512

22. Danilowicz, C., Limouse, C., Hatch, K., Conover, A., Coljee, V.W., Kleckner, N., Prentiss, M.: The structure of DNA overstretched from the $5^{\prime} 5^{\prime}$ ends differs from the structure of DNA overstretched from 
the 3'3' ends. Proc. Natl. Acad. Sci. U. S. A. 106(32), 13196-13201 (2009). https://doi.org/10.1073 /pnas.0904729106

23. Zhang, X., Chen, H., Fu, H., Doyle, P.S., Yan, J.: Two distinct overstretched DNA structures revealed by single-molecule thermodynamics measurements. Proc. Natl. Acad. Sci. U. S. A. 109(21), 8103-8108 (2012). https://doi.org/10.1073/pnas.1109824109

24. Lee, G., Muramoto, G.G., Chute, J.P., Marszalek, P.E.: Nanomechanical fingerprints of gamma radiation damage to DNA. J. Nanosci. Nanotechnol. 9(12), 7359-7363 (2009)

25. Manning, G.S.: Electrostatic free energy of the DNA double helix in counterion condensation theory. Biophys. Chem. 101-102, 461-473 (2002)

26. Rouzina, I., Bloomfield, V.A.: Force-induced melting of the DNA double helix. 2. Effect of solution conditions. Biophys. J. 80(2), 894-900 (2001). https://doi.org/10.1016/s0006-3495(01)76068-7

27. King, G.A., Gross, P., Bockelmann, U., Modesti, M., Wuite, G.J., Peterman, E.J.: Revealing the competition between peeled ssDNA, melting bubbles, and S-DNA during DNA overstretching using fluorescence microscopy. Proc. Natl. Acad. Sci. U. S. A. 110(10), 3859-3864 (2013). https://doi.org/10.1073 /pnas. 1213676110

28. Bosaeus, N., El-Sagheer, A.H., Brown, T., Akerman, B., Norden, B.: Force-induced melting of DNAevidence for peeling and internal melting from force spectra on short synthetic duplex sequences. Nucleic Acids Res. 42(12), 8083-8091 (2014). https://doi.org/10.1093/nar/gku441

29. Xu, S., Yuan, H., Xu, A., Wang, J., Wu, L.: Rapid synthesis of stable and functional conjugates of DNA/ gold nanoparticles mediated by Tween 80. Langmuir 27(22), 13629-13634 (2011). https://doi.org/10.1021 /la203632c

30. Daniel, M.C., Astruc, D.: Gold nanoparticles: assembly, supramolecular chemistry, quantum-size-related properties, and applications toward biology, catalysis, and nanotechnology. Chem. Rev. 104(1), 293-346 (2004). https://doi.org/10.1021/cr030698+

31. Krpetic, Z., Singh, I., Su, W., Guerrini, L., Faulds, K., Burley, G.A., Graham, D.: Directed assembly of DNA-functionalized gold nanoparticles using pyrrole-imidazole polyamides. J. Am. Chem. Soc. 134(20), 8356-8359 (2012). https://doi.org/10.1021/ja3014924

32. Metzler, R., Ambjornsson, T., Hanke, A., Fogedby, H.C.: Single DNA denaturation and bubble dynamics. J Phys. Condens. Matter 21(3), 034111 (2009). https://doi.org/10.1088/0953-8984/21/3/034111

33. Singh, A.R., Giri, D., Kumar, S.: Force induced melting of the constrained DNA. J. Chem. Phys. 132(23), 235105 (2010). https://doi.org/10.1063/1.3427587

34. Yang, T.S., Cui, Y., Wu, C.M., Lo, J.M., Chiang, C.S., Shu, W.Y., Chung, W.J., Yu, C.S., Chiang, K.N., Hsu, I.C.: Determining the zero-force binding energetics of an intercalated DNA complex by a singlemolecule approach. ChemPhysChem 10(16), 2791-2794 (2009). https://doi.org/10.1002/cphc.200900435

35. Bayas, M.V., Leung, A., Evans, E., Leckband, D.: Lifetime measurements reveal kinetic differences between homophilic cadherin bonds. Biophys. J. 90(4), 1385-1395 (2006). https://doi.org/10.1529 /biophysj.105.069583

36. Shi, Q., Chien, Y.H., Leckband, D.: Biophysical properties of cadherin bonds do not predict cell sorting. J. Biol. Chem. 283(42), 28454-28463 (2008). https://doi.org/10.1074/jbc.M802563200

37. Dudko, O.K., Hummer, G., Szabo, A.: Intrinsic rates and activation free energies from single-molecule pulling experiments. Phys. Rev. Lett. 96(10), 108101 (2006). https://doi.org/10.1103 /PhysRevLett.96.108101

38. Dudko, O.K., Hummer, G., Szabo, A.: Theory, analysis, and interpretation of single-molecule force spectroscopy experiments. Proc. Natl. Acad. Sci. U. S. A. 105(41), 15755-15760 (2008). https://doi. org/10.1073/pnas.0806085105

39. Ambjornsson, T., Banik, S.K., Krichevsky, O., Metzler, R.: Breathing dynamics in heteropolymer DNA. Biophys. J. 92(8), 2674-2684 (2007). https://doi.org/10.1529/biophysj.106.095935

40. Wenner, J.R., Williams, M.C., Rouzina, I., Bloomfield, V.A.: Salt dependence of the elasticity and overstretching transition of single DNA molecules. Biophys. J. 82(6), 3160-3169 (2002). https://doi. org/10.1016/s0006-3495(02)75658-0

41. Murade, C.U., Subramaniam, V., Otto, C., Bennink, M.L.: Force spectroscopy and fluorescence microscopy of dsDNA-YOYO-1 complexes: implications for the structure of dsDNA in the overstretching region. Nucleic Acids Res. 38(10), 3423-3431 (2010). https://doi.org/10.1093/nar/gkq034

42. Ota, T., Sugiura, T., Kawata, S.: Rupture force measurement of biotin-streptavidin bonds using optical trapping. Appl. Phys. Lett. 87(4), 043901 (2005). https://doi.org/10.1063/1.1999855 